\title{
PENGARUH ATTRIBUTES, BENEFITS DAN ATTITUDINAL LOYALTY MEMILIKI DAMPAK TERHADAP BEHAVIORAL LOYALTY PADA FANS PERSIB BANDUNG DALAM INDUSTRI SEPAKBOLA INDONESIA
}

\author{
AULIA DANIBRATA \\ KLEMENS WEDANAJI PRASASTYO \\ ALZA \\ Trisakti School of Management, Jl Kyai Tapa no. 20 Jakarta, Indonesia \\ dani@stietrisakti.ac.id, klemens@stietrisakti.ac.id
}

\begin{abstract}
The purpose of this study was to determine the effect of attributes, benefits and attitudinal loyalty has a impact on behavioral loyalty in Bandung fans in the Indonesian football industry. This research is expected to be able to improve the results of previous studies. The population of this study came from fans of Persib Bandung who have a domicile in West Java, had watched Persib Bandung directly and had bought Persib Bandung merchandise. The researcher chose 100 respondents as the sample for this study, used insidental sampling as a sampling technique, and used a questionnaire for data collection. This study uses structural equation modeling as a research model. In addition, SPSS and Warp PLS 3.0 are used as statistical tools. The results of this study indicate that attributes and benefits affect attitudinal loyalty, and attitudinal loyalty has an effect on behavioral loyalty.
\end{abstract}

Keywords: Attributes, benefits, attitude loyalty, behavioral loyalty

Abstrak: Tujuan penelitian adalah untuk mengetahui pengaruh attributes, benefits dan attitudinal loyalty memiliki dampak terhadap behavioral loyalty pada fans Perib Bandung dalam industri sepakbola Indonesia. Penelitian ini diharapkan mampu untuk meningkatkan hasil penelitian sebelumnya. Populasi penelitian ini berasal dari fans Persib Bandung yang memiliki domisili di Jawa Barat, pernah menonton Persib Bandung secara langsung dan pernah membeli merchandise Persib Bandung. Peneliti memilih 100 responden sebagai sampel untuk penelitian ini, menggunakan insidental sampling sebagai teknik sampling, dan menggunakan kuesioner untuk pengumpulan data. Penelitian ini menggunakan structural equation modelling sebagai model penelitian. Selain itu, SPSS dan Warp PLS 3.0 digunakan sebagai alat statistik. Hasil penelitian ini menunjukan bahwa attributes dan benefits berpengaruh terhadap attitudinal loyalty, serta attitudinal loyalty berpengaruh terhadap behavioral loyalty.

Kata kunci: Attributes, benefits, attitude loyalty, behavioral loyalty

\section{PENDAHULUAN}

Dalam arti luas industri dikatakan segala kegiatan ekonomi yang bersifat produktif atau menghasilkan keuntungan. Di Indonesia industri begitu banyak seperti data Badan Pusat Statistik. Badan Pusat Statistik membagi industri yang ada di Indonesia menjadi 14.jenis industri. Di dalam data tersebut dapat dilihat industri informasi dan komunikasi terus meningkat dari tahun 2015 sebesar 8.7 mengalami kenaikan di tahun 2016 sebesar 8.88 dan kenaikan tertinggi di tahun 2017 sebesar 9.81 Ini menunjukan 
bahwa industri informasi terus berkembang seiring kemajuan zaman.

Perkembangan perekonomian yang semakin cepat, hal ini memunculkan industriindustri baru di Indonesia. Berawal dari inggris, ekonomi industri kreatif kini banyak diadopsi negara-negara berkembang seperti Indonesia. Badan Ekonomi Kreatif Indonesia telah menetapkan 16 subsektor yang didukung dalam industri kreatif. Berdasarkan riset yang dilakukan Bekraf dan Badan Pusat Statistik, industri kreatif memberikan pengaruh terhadap ekonomi di indonesia yang mendominasi ada 3 subsektor. Data bekraf pada 2016 menyebutkan bahwa di 3 subsektor tersebut yaitu kuliner 41,69 persen, fashion 18,15 persen dan kriya 15,70 persen.

Di era digital sekarang ini, salah satu perusahaan yang bergerak di bidang jasa dan konsultasi Media Partner Asia (MPA) mengatakan dalam marketeers.com menemukan sesuatu yang menarik seputar hak siar program olahraga. Di dalam penelitiannya yang berjudul Asia Pasific Sport In The Age of Streaming, nilai pasar dari hak siar media olahraga asia pasifik (di luar China) tahun 2018 mencapai USS 5 Miliar atau sekitar Rp 70 triliun. Jumlah ini meningkat dari tahun sebelumnya hal ini disebabkan karena tahun 2018 diadakannya World Cup di Rusia.

Di Indonesia sendiri, organisasi sepakbola indonesia (PSSI) telah menjelaskan mengenai sejarah sepakbola di Indonesia. PSSI yang dibentuk pada 19 April 1930 saat ini telah mewadahi pertandinganpertandingan yang terdiri dari pertandingan dalam negeri yang diselenggarakan oleh pihak perkumpulan atau klub sepakbola, pengurus cabang, pengurus daerah yang sudah disusun dalam kalender kegiatan tahunan PSSI. Dalam perkembangannya PSSI sekarang memperluas jenis kompetisi dan pertandingan yang dinaunginya. Saat ini terdapat 18 klub yang telah terdaftar di PT Liga Indonesia yang telah bergulir, klub-klub tersebut bersaing untuk memperebutkan trofi Liga 1 Indonesia. Yaitu Arema FC ,Bali United, Bhayangkara FC, Borneo FC, Madura United FC, Mitra Kukar Fc, Persebaya,Persela Lamongan,Perseru,Persib Bandung,Persija Jakarta,Persipura Jayapura,Ps Barito Putera,Ps Tira,Psis Semarang,Psm Makassar,Psms Medan, dan Sriwijaya Fc.

Salah satu klub sepakbola di Indonesia yang memiliki tingkat fanatisme yang tinggi adalah Persib Bandung, dibuktikan dengan data dari web resmi klub Persib Bandung. Rata-rata jumlah penonton di pertandingan Persib Bandung di stadion Gelora Bandung Lautan Api paling tinggi di kompetisi sepak bola Liga 1, musim 2018 laga Persib di kandang rata-rata ditonton 72.781 penonton. Dimana pertandingan melawan Mitra Kukar di Stadion Gelora Bandung Lautan Api pada 8 April 2018 menjadi yang paling banyak dihadiri oleh bobotoh yaitu sebesar 32.715 penonton.

Selanjutnya di posisi kedua pertandingan melawan Arema fc di Kanjuruhan Malang dihadiri oleh bobotoh sebesar 31.653 penonton, walaupun jarak yang jauh dan bukan merupakan pertandingan kandang bobotoh tetap hadir dan mendukung tim kesayangan mereka bertanding. Jumlah penonton yang hadir ke stadion paling sedikit saat Persib Bandung menghadapi PS Tira dimana hanya dihadiri oleh 9787 penonton. Menjadi kan pertandingan ini merupakan jumlah penonton terendah selama kompetisi Liga 1 Indonesia bergulir tahun ini. Dengan data tersebut membuktikan bahwa klub Persib Bandung sangat mengandalkan pendapatan klub nya melalui pemasukan tiket penonton pada lagalaga yang dimainkannya. 


\section{Attributes}

Attributes adalah unsur-unsur yang melekat pada suatu produk atau jasa yang memiliki manfaat sehingga menjadi keputusan pembelian oleh konsumen.

Seperti dinyatakan Gladden dan Funk (2001) dalam mederer (2016) attributes adalah Kunci dari seorang fans untuk menjadi loyal. Menurut Peter dan Olson (2005) attributes adalah karakteristik sebuah produk bisa berwujud,subjektif atau fisik dan tidak berwujud,subjektif atau fisik. Selanjutnya Aeker,Kumar,Day

$(2004,753)$ mengemukakan bahwa atribut adalah karakteristik untuk sebuah objek atau orang.

\section{Benefits}

Menurut Lovelock dan Wirtz $(2016,764)$ berpendapat bahwa benefits adalah keuntungan atau kelebihan dalam menggunakan atau membutuhkan sebuah produk atau jasa. Sedangkan menurut Cron dan Decalor $(2010,143)$ benfit adalah pernyataan tengtang bagaimana suatu produk atau layanan dapat membantu pelanggan memenuhi kebutuhan eksplisit atau yang dinyatakan. Menurut Tjiptono $(2014,419)$ menyatakan bahwa benefits adalah manfaat berupa keyakinan atau trust terhadap penyedia jasa dan berkurangnya ketidakpastian menyangkut kinerja yang bakal diterima.

Jadi dapat disimpulkan bahwa benefits merupakan keuntungan atau manfaat yang didapat oleh konsumen terhadap jasa yang diberikan, sehingga membuat konsumen tersebut puas dan melakukan pembelian kembali.

Benefits dalam konteks sepakbola terkait dengan peningkatan keterlibatan dan interaksi dengan klub, terutama manfaat berdasarkan pengalaman seperti nostalgia dan escape. Bauer et al (2008) dalam Maderer e(2016)

\section{Attitudinal Loyalty}

Menurut Lovelock dan Wirtz $(2016,476)$

Attitudinal Loyalty mengacu kepada kesukaan sejati dan keterkaitan emosional dari perusahaan,layanan dan merek. Menurut Krosnicket (1993) dalam Maderer (2016) Attitudinal Loyalty dalam konteks olahraga adalah trdiri dsri pengetahuan tentang klub dalam kehidupan atau penggemar, dan sejauh mana penggemar secara pribadi merasakan keberhasilan dan kegagalan tim. Sedangkan menurut Shanker (2000) dalam Schijns (2003) "Attitudinal Loyalty mewakili pesanan yang lebih tinggi, atau komitmen jangka panjang pelanggan kepada organisasi yang tidak dapat disimpulkan hanya dengan mengamati perilaku pembelian berulang pelanggan. Attitidinal Loyalty penting karena menunjukan kecenderungan untuk menampilkan sikap tertentu,seperti kemunginan pengguna di masa depan.

\section{Behavioral Loyalty}

Menurut Lovelock dan Wirtz $(2016,476) \quad$ Behavioral Loyalty termasuk perilaku sperti membeli kembali mengeluarkan uang yang banyak dan membeikan kalimat positif dari mulut ke mulut. Shiftfman dan Kanuk $(2010,93)$ mengemukakan bahwa Behavioral Loyalty adalah frekuensi dan konsistensi membeli merek tertentu. Sedangkan menurut Bloemer dan Oderkerken-Schroder dalam Omar et al (2007) Behavioral Loyalty adalah pelanggan yang merasa sangat kuat sehingga perusahaan anda dapat memenuhi kebutuhannya yang terbaik sehingga persaingan perusahaan anda secara virtual dikecualikan dari set pertimbangan.

Berdasarkan kerangka pemikiran dan teori-teori yang diadaptasi oleh Antoni Serra Cantallops (2018) dirumuskan hipotesis sebagai berikut:

$\mathrm{H}_{1} \quad$ Terdapat pengaruh Attributes terhadap Attitudinal Loyalty fans Persib Bandung. 
$\mathrm{H}_{2}$ Terdapat pengaruh Benefits terhadap Attitudinal Loyalty fans Persib Bandung.

$\mathrm{H}_{3} \quad$ Terdapat pengaruh Attitudinal Loyalty terhadap Behavioral Loyalty fans Persib Bandung.

\section{METODE PENELITIAN}

Rancangan penelitian yang digunakan dalam penelitian ini adalah penelitian deskriptif dan penelitian kausalitas. Sekaran dan Bougie (2016, 43) menyatakan bahwa penelitian deskriptif adalah studi deskriptif sering dirancang untuk mengumpulkan data yang menggambarkan karakteristik objek (seperti orang,organisasi,produk,merek) peristiwa, atau situasi. Sedangkan penelitian kausal menurut Sekaran dan Bougie $(2016,44)$ adalah peneiliti tertarik untuk melukiskan satu atau lebih faktor yang menyebabkan masalah. Jadi penelitian ini adalah untuk memprediksi hubungan sebabakibat antar variabel yang terkait sesuai dengan karakteristik-karakteristik yang sesuai dengan kebutuhan penelitian.

Populasi pada penelitian ini adalah fans Persib Bandung, karena dianggap mampu memahami fenomena dan butiran kuesioner yang diberikan. Pengumpulan data sampel dalam penelitian ini menggunakan kuesioner yang disebarkan pada bulan April 2019 s/d Juni 2019 di Camp Viking Bogor dan Stadion Si Jalak Harupat Soreang Bandung. Sedangkan jumlah sampel yang diambil oleh peneliti berdasarkan pertimbangan-pertimbangan yang dilakukan oleh beberapa pakar statistika. Menurut Sekaran Bougie $(2016,264)$ "Samples sizes larger than 30 and less than 500 are appropriate for most research. In multivariate research, the sample size should be several times (preferably ten times or more) as large as the number of variables in the study". Penelitian ini akan mengambil sampel sebanyak 100 karena data yang mampu memenuhi kriteria fans Persib Bandung yang telah ditentukan untuk diteliti.

Sampel diambil dengan menggunakan teknik non-probability sampling di dalam penelitian ini. Teknik non-probability sampling yang digunakan di dalam penelitian ini menggunakan metode insidental sampling. Sugiyono $(2008,122)$ mengatakan bahwa, "insidental sampling adalah teknik penentuan sampel berdasarkan kebetulan, yaitu siapa saja yang secara kebetulan/insidentalbertemu dengan peneliti dapat digunakan sebagai sampel, bila dipandang orang yang kebetulan itu cocok sebagai sumber data." Kriteria sampel berdasarkan hasil teknik sampling secara insidental dalam penelitian ini adalah responden merupakan fans persib bandung, responden yang pernah menonton persib bandung setahun terakhir di stadion,pernah membeli merchandise selama setahun terkahir dan merupakan warga Jawa Barat.

Skala yang digunakan dalam penelitian ini adalah skala likert. Pertanyaan kuisioner terstruktur menggunakan skala 1-5, dari sangat tidak setuju sampai sangat setuju.

\section{HASIL}

Berdasarkan dari hasil pengolahan kuisioner, maka karakteristik responden sebagai berikut: 
Tabel 1 Karakteristik Responden

\begin{tabular}{llc}
\hline Keterangan & Deskripsi & Jumlah \\
\hline \multirow{2}{*}{ Jenis Kelamin } & Laki-laki & 82 \\
& Perempuan & 18 \\
\hline \multirow{4}{*}{ Usia } & $<$ 19 Tahun & 21 \\
& 19 -23 Tahun & 26 \\
& 24 - 28 Tahun & 28 \\
& 29 - 33 Tahun & 14 \\
& 34 - 38 Tahun & 1 \\
& $>38$ Tahun & 10 \\
\hline \multirow{4}{*}{ Frekuensi menonton Persib Bandung } & 5 kali & 23 \\
& 5 s/d 10 kali & 2 \\
& 10 s/d 15 kali & 25 \\
& 15 s/d 20 kali & 3 \\
Frekuensi Pembelian Marchandise & $>20$ kali & 21 \\
\hline & 1 s/d 3 kali & 27 \\
& 3 s/d 5 kali & 36 \\
& $>5$ kali & 37 \\
\hline
\end{tabular}

Tabel 2 Hasil Pengujian Validitas dan Reliabilitas

\begin{tabular}{|c|c|c|c|c|c|c|c|c|c|c|}
\hline \multirow{3}{*}{ Variabel } & \multirow{3}{*}{ Indikator } & \multirow{2}{*}{\multicolumn{3}{|c|}{ Convergent Validity }} & \multirow{3}{*}{$\begin{array}{l}\text { ग0 } \\
\text { 롯 } \\
\text { 츰 }\end{array}$} & \multirow{2}{*}{\multicolumn{2}{|c|}{$\begin{array}{l}\text { Average } \\
\text { Variance } \\
\text { Extracted } \\
\text { AVE }>0.5\end{array}$}} & \multirow{3}{*}{\begin{tabular}{|c|}
$\begin{array}{c}\text { Composit } \\
\text { e reliability }\end{array}$ \\
$\mathrm{CR}>0.7$ \\
$\mathrm{CR}$ \\
\end{tabular}} & \multirow{3}{*}{\begin{tabular}{|c}
$\begin{array}{c}\text { Cronbach' } \\
\text { s Alpha }\end{array}$ \\
$\begin{array}{c}\text { Alpha }> \\
0.5\end{array}$ \\
Alpha
\end{tabular}} & \multirow{3}{*}{ Desc } \\
\hline & & & & & & & & & & \\
\hline & & $\begin{array}{c}\text { Loading } \\
\text { Factor }\end{array}$ & $P$ - value & Desc & & AVE & Desc & & & \\
\hline \multirow{16}{*}{ A } & SU1 & 0,894 & $<0.000$ & Valid & 2 & \multirow{16}{*}{0.500} & \multirow{16}{*}{ Valid } & \multirow{16}{*}{0.941} & \multirow{16}{*}{0.930} & \multirow{16}{*}{$\begin{array}{c}\text { Relia } \\
\text { bel }\end{array}$} \\
\hline & SU2 & 0,811 & $<0.000$ & Valid & 8 & & & & & \\
\hline & SU3 & 0,791 & $<0.000$ & Valid & 11 & & & & & \\
\hline & SP1 & 0,612 & $<0.000$ & Valid & 15 & & & & & \\
\hline & SP2 & 0,588 & $<0.000$ & Valid & 17 & & & & & \\
\hline & $\mathrm{HC} 1$ & 0,994 & $<0.000$ & Valid & 1 & & & & & \\
\hline & $\mathrm{HC} 2$ & 0,737 & $<0.000$ & Valid & 14 & & & & & \\
\hline & $\mathrm{HC} 3$ & 0,850 & $<0.000$ & Valid & 4 & & & & & \\
\hline & L01 & 0,758 & $<0.000$ & Valid & 13 & & & & & \\
\hline & LO2 & 0,793 & $<0.000$ & Valid & 9 & & & & & \\
\hline & LO3 & 0,710 & $<0.000$ & Valid & 15 & & & & & \\
\hline & ST1 & 0,791 & $<0.000$ & Valid & 10 & & & & & \\
\hline & ST2 & 0,822 & $<0.000$ & Valid & 7 & & & & & \\
\hline & ST3 & 0,588 & $<0.000$ & Valid & 16 & & & & & \\
\hline & PD1 & 0,828 & $<0.000$ & Valid & 6 & & & & & \\
\hline & PD2 & 0,849 & $<0.000$ & Valid & 5 & & & & & \\
\hline
\end{tabular}




\begin{tabular}{|c|c|c|c|c|c|c|c|c|c|c|}
\hline & PD3 & 0,867 & $<0.000$ & Valid & 3 & & & & & \\
\hline & TR1 & 0,858 & $<0.000$ & Valid & 4 & & & & & \\
\hline & TR2 & 0,770 & $<0.000$ & Valid & 12 & & & & & \\
\hline \multirow{9}{*}{ B } & ES1 & 0,690 & $<0.000$ & Valid & 8 & \multirow{9}{*}{0.650} & \multirow{9}{*}{ Valid } & \multirow{9}{*}{0.943} & \multirow{9}{*}{0.932} & \multirow{9}{*}{$\begin{array}{c}\text { Relia } \\
\text { bel }\end{array}$} \\
\hline & ES2 & 0.782 & $<0.000$ & Valid & 7 & & & & & \\
\hline & ES3 & 0.682 & $<0.000$ & Valid & 9 & & & & & \\
\hline & N01 & 0.868 & $<0.000$ & Valid & 1 & & & & & \\
\hline & NO2 & 0.865 & $<0.000$ & Valid & 2 & & & & & \\
\hline & NO3 & 0.858 & $<0.000$ & Valid & 3 & & & & & \\
\hline & PIP1 & 0.805 & $<0.000$ & Valid & 6 & & & & & \\
\hline & PIP2 & 0.835 & $<0.000$ & Valid & 5 & & & & & \\
\hline & PIP3 & 0.842 & $<0.000$ & Valid & 4 & & & & & \\
\hline \multirow{14}{*}{$\mathrm{AL}$} & AL1 & 0.635 & $<0.000$ & Valid & 14 & \multirow{3}{*}{0.515} & \multirow{3}{*}{ Valid } & \multirow{3}{*}{0.863} & \multirow{3}{*}{0.815} & \multirow{3}{*}{$\begin{array}{c}\text { Relia } \\
\text { bel }\end{array}$} \\
\hline & AL2 & 0.777 & $<0.000$ & Valid & 10 & & & & & \\
\hline & AL3 & 0.861 & $<0.000$ & Valid & 7 & & & & & \\
\hline & AL4 & 0.869 & $<0.000$ & Valid & 6 & & & & & \\
\hline & AL5 & 0.929 & $<0.000$ & Valid & 3 & & & & & \\
\hline & AL6 & 0.945 & $<0.000$ & Valid & 2 & & & & & \\
\hline & AL7 & 0.771 & $<0.000$ & Valid & 12 & & & & & \\
\hline & AL8 & 0.774 & $<0.000$ & Valid & 11 & & & & & \\
\hline & AL9 & 0.804 & $<0.000$ & Valid & 9 & & & & & \\
\hline & AL10 & 0.900 & $<0.000$ & Valid & 5 & & & & & \\
\hline & AL11 & 0.926 & $<0.000$ & Valid & 4 & & & & & \\
\hline & AL12 & 0.947 & $<0.000$ & Valid & 1 & & & & & \\
\hline & AL13 & 0.652 & $<0.000$ & Valid & 13 & & & & & \\
\hline & AL14 & 0.834 & $<0.000$ & Valid & 8 & & & & & \\
\hline \multirow{6}{*}{$B L$} & $\mathrm{BL1}$ & 0.638 & $<0.000$ & Valid & 5 & \multirow{6}{*}{0.515} & \multirow{6}{*}{ Valid } & \multirow{6}{*}{0.852} & \multirow{6}{*}{0.783} & \multirow{6}{*}{$\begin{array}{c}\text { Relia } \\
\text { bel }\end{array}$} \\
\hline & $\mathrm{BL} 2$ & 0.625 & $<0.000$ & Valid & 6 & & & & & \\
\hline & BL3 & 0.818 & $<0.000$ & Valid & 3 & & & & & \\
\hline & BL4 & 0.845 & $<0.000$ & Valid & 1 & & & & & \\
\hline & BL5 & 0.817 & $<0.000$ & Valid & 4 & & & & & \\
\hline & BL6 & 0.819 & $<0.000$ & Valid & 2 & & & & & \\
\hline
\end{tabular}

Nilai batas yang digunakan untuk menilai sebuah tingkat validitas dan reliabilitas yang dapat diterima adalah $\mathrm{AVE}>0.5, \mathrm{~A}>0,5>$ 0,7 dan alpha $>0,5$. Nilai AVE, A dan alpha dari semua variabel melebihi cut off value sehingga kesimpulan yang dapat diambil adalah variabel attributes,benefit, attitudinal loyalty dan behavioral loyalty ialah valid dan reliabel. Selain itu, hasil pengujian ini menunjukkan bahwa seluruh indikator pada konstruk tersebut mampu menjelaskan variabel laten atau konstruk yang dibentuknya. 
Tabel 3 Pengujian Hipotesis Pengaruh Langsung

\begin{tabular}{ccccc}
\hline $\begin{array}{c}\text { Variabel } \\
\text { Independen }\end{array}$ & $\begin{array}{c}\text { Variabel } \\
\text { Dependen }\end{array}$ & $\begin{array}{c}\text { Path } \\
\text { Coefficient }\end{array}$ & P-Value & Kesimpulan \\
\hline $\mathrm{A}$ & $\mathrm{AL}$ & 0.469 & 0.000 & Highly Significant \\
$\mathrm{B}$ & $\mathrm{AL}$ & 0.433 & 0.000 & Highly Significant \\
$\mathrm{AL}$ & $\mathrm{BL}$ & 0.790 & 0.000 & Highly Significant \\
\hline
\end{tabular}

Nilai $p$-value atau $0,000<0,05$, maka $\mathrm{Ha}$ diterima. Artinya, terdapat pengaruh signifikansi yang tinggi (Highly significant) Attributes terhadap Attitudinal Loyalty pada fans Persib Bandung.

Nilai $p$-value atau $0,000>0,05$, maka $\mathrm{Ha}$ diterima. Artinya, terdapat pengaruh signifikansi yang tinggi (Highly significant) benefits terhadap Attitudinal Loyalty loyalty pada fans Persib Bandung.

Nilai $p$-value atau $0,000<0,05$, maka $\mathrm{Ha}$ diterima. Artinya, terdapat pengaruh signifikansi yang tinggi (Highly significant) Attitudinal Loyalty terhadap Behavioral loyalty pada fans Persib Bandung.

\section{PENUTUP}

Penelitian ini bertujuan untuk melihat pengaruh attributes, benefit dan attitudinal loyalty terhadap behavioral loyalty pada fans
Persib Bandung. Berdasarkan pembahasan dan penelitian yang dijelaskan pada bab sebelumnya terdapat kesimpulan dari 3 hipotesis yang ada, serta terdapat 3 hipotesis yang berpengaruh. Penulis menyadari bahwa adanya keterbatasan pada penelitian ini. Keterbatasan yang ada pada penelitian ini antara lain: (1) Penelitian hanya mendatangi satu stadion Persib Bandung, dan juga jumlah responden yang mewakili hanya 100 responden yang mampu mewakili para fans Persib Bandung, (2) Keterbatasan waktu yang dimiliki didalam pengumpulan kuisioner dari para responden dan pengolahan data penelitian yang didapatkan, dan (3) Kekurangan pengetahuan pengolahan data dengan software yang belum pernah digunakan sebelumnya selama perkuliahan, yaitu Warp PLS. 


\section{REFERENCES:}

Aaker, Kumar, Day.2004.Marketing Research 8th edition.New Jersey: John Wiley and Sons.

Blackwell, Roger D., Paul W. Miniard and James F Engel.2006. Consumer Behavior 10th edition. International Student Edition. Thomson South Western.

Clow, Kenneth E.2018.Integrated Advertising Promotion, and Marketing Communications 8 edition.Malaysia:Perason Education,PTE,LTD.

Cron, William L and Decalor Thomas E.2010.Sales management concept and cases 10 edition.New Jersey:Jhon Wiley and Sons.

Ghozali, Imam dan Karlina Aprilia Kusumadewi. 2013. Teknik penyusunan skala likert (summated likert) dalam penelitian akuntansi dan bisnis. Semarang: Fatawa Publishing.

Hair, Joseph F., G. Tomas M. Hult, Christian M. Ringle, and Marko Sarstedt. 2014. A primer on partial least squares structural equation modeling (PLS-SEM) 4th edition. Los Angeles: SAGE.

Hair, Joseph F., G. Tomas M. Hult, Christian M. Ringle, and Marko Sarstedt. 2017. A primer on partial least squares structural equation modeling (PLS-SEM) 2nd edition. Los Angeles: SAGE.

Kotler, Philip and Armstrong Gary.2014.Principles of Marketing 15 edition.England:Pearson Education.

Lovelock, Christopher and Wirtz Jochen.2016.Service Marketing people technology strategy.New Jersey:World Scientific.

Maderer, Daniel., Holtbruegge Dirk, and Woodland Rachel.2016.The impact of Brand Associations on Brand Loyalty in the football industry. Journal of the emerald, www.emeraldinsight.com/2042-678x.htm (diakses pada 13 maret 2018).

Omar,Nor Asiah,Rosidah Musa,Muhammad Azrin Nazri.2007."program perceived value and program satisfaction influences on store loyalty".Gadjah Mada International Journal of Business Vol.9 No.3 pp.363.

Peter, J Paul and Olson Jerry C.2005. Consumer behavior and marketing strategy 7 edition. Mc Graw-Hill Irwin.

Schiffman, Leon $G$ and Wisenblit Joseph.2015.Consumer Behavior 11 edition.England: Pearson Education.

Schiffman, Leon G., dan Joseph L. Wisenblit. 2015. Consumer Behavior 11th Edition. Essex: Pearson Education Limited.

Schiffman, Leon G.,Kanuk Leslie Lazar and Wisenblit Joseph.2010.Consumer Behavior 10 edition.New Jersey: Pearson.

Sekaran, Uma and Roger Bougie. 2016. Research methods for business : a skill-building approach 7th edition. United Kingdom: John Wiley and Sons.

Sugiyono. 2016. Metode penelitian dan pengembangan (research dan pengembangan). Bandung: Alfabeta.

Tjiptono, Fandy.2014.Pemasaran Jasa (Prinsip,Penerapan,Penelitian). Yogyakarta: ANDI 